\title{
Improving Students' Critical Thinking through Oral Questioning in Mathematics Teaching
}

\author{
Muhammad Sofwan Mahmud, Wan Ahmad Munsif Wan Pa*, \\ Mohd Syazwan Zainal and Nadia Fasha Mohd Drus \\ Universiti Kebangsaan Malaysia, Selangor, Malaysia \\ https:/ / orcid.org/0000-0002-0504-4622 \\ https://orcid.org/0000-0001-6218-4376 \\ https://orcid.org/0000-0002-1450-2760 \\ https://orcid.org/0000-0002-4669-3821
}

\begin{abstract}
The use of effective oral questioning in the teaching of mathematics can stimulate students' thinking and encourage them to think critically. As a result, this study was carried out to identify the oral questions used by teachers when teaching mathematics. This can encourage students' critical thinking. This was a qualitative study in the form of a case study conducted in six schools in a Malaysian state with a total of six study participants. They were chosen on purpose based on the specific criteria set by the researcher. The data was collected using observation methods, interviews, and field notes to gain an in-depth picture of the phenomena studied. The study findings were analyzed using the continuous comparison method to identify the themes and subthemes involved. The researchers used several methods to improve the validity and reliability of this study, including triangulation, the consent of the study participants, peer reviews, audit trails, researcher bias, and a long period in the field. According to the study findings, mathematics teachers frequently use three types of oral questions to encourage their students to think critically: prompting questions, reflective questions, and clarification questions. These types of oral questions are effective at encouraging students to think critically when trying to solve mathematical problems. This study implies that teachers should use caution when asking oral questions so that the students' thinking is stimulated, rather than focusing on memorizing important mathematical algorithms and procedures.
\end{abstract}

Keywords: critical thinking; oral questioning; teaching mathematics

\section{Introduction}

Encouraging students to think critically when teaching and learning mathematics is a significant challenge for teachers (Mahmud, 2019). This is due to the changes

*Corresponding author: Wan Ahmad Munsif Wan Pa; Email: munsif@ukm.edu.my 
in contemporary education policy, which emphasizes thinking skills. This makes thinking skills a priority for every teacher when teaching mathematics, as opposed to the traditional teaching styles that only emphasize the memorization of the critical formulas and procedures necessary to solve mathematical problems (Alhassora et al., 2017). However well intentioned, encouraging and fostering this form of thinking in students is not an easy task as it requires teachers to use various approaches in their mathematics teaching. This study was conducted to identify the type of questions that mathematics teachers use to enhance students' critical thinking in mathematics teaching.

Oral questioning can help in the development of higher order thinking skills, including stimulating students' thinking, increasing their inquiry into and exploration of mathematics, and piquing their interest in the subject taught (Hassan et al., 2016). Oral questioning can also assist teachers in determining the extent to which the students understand the content of their lessons, helping them to better plan any interventions required (Çelik \& Güzel, 2016). By selecting the most appropriate type of oral question to use during the teaching process, teachers can accomplish their teaching objectives more efficiently and stimulate their students' thinking. It is necessary to ensure that teachers consistently use oral questioning given the importance of teaching students how to think critically. It is an art that every teacher must master and practice (Curriculum Development Division, 2013).

With that in mind, the use of oral questioning techniques in mathematics teaching also improves students' conceptual and contextual understanding of what is being learned (Kassim \& Zakaria, 2013). The students' understanding and thinking will be developed further because they are continuously stimulated by the questioning of the activities with which they are busy (Wong, 2015). Moreover, Wong (2015) also stated that oral questioning allows teachers to pry out their students' thoughts to get more accurate answers when teachers are not satisfied with the initial answers. In this context, the students' thinking should be explored by increasing the number of open-ended questions.

To this end, the students' ideas and knowledge can be developed to help them understand the new content they are learning (Desli \& Galanopoulou, 2017). Additionally, it also creates more active students and a more enjoyable teaching process. The students can share their ideas and thoughts, and this encourages effective communication between teachers and students, which is one the key standards of 21st century education (Institut Aminuddin Baki, 2017). The knowledge obtained through oral questioning can also promote the assimilation of knowledge that the students may already have. Their new knowledge can be adapted to the existing scheme, as described in Piaget's theory of cognitive development (Mahmud et al., 2020a).

Combs et al. (2009) created a conceptual model of both critical and creative thinking processes (Figure 1). They defined critical and creative thinking as an integrated process that involves the production and refinement of ideas around a knowledge core. Self-regulatory behaviour is used to monitor and manage idea 
production and the refining processes. This behaviour includes goal setting and the monitoring of the achievement of those goals, all while preserving the essential attitudes and dispositions. The processes of idea generation and refinement are monitored and controlled by self-regulation. All the components discussed in the framework can be linked to the role of oral questioning in instilling critical and creative thinking in learning mathematics. Creating ideas can be improved through effective oral questioning activities in which the teachers can stimulate their students' existing knowledge to develop new ideas and information. However, when teaching mathematics, the interaction with knowledgeable peers is essential to help students develop self-regulation as a scaffolding to gain and adapt new knowledge alongside their preexisting knowledge.

In the reflective judgment component of critical and creative thinking, oral questioning serves as a thinking tool. Oral questioning can stimulate students to develop plans and solutions to mathematical problems that arise in a structured manner based on the ideas generated previously. In this environment, students analyze and pick out the ideas developed from their personal knowledge and experience. This is received through the analysis and review of the ideas and resources of others when they engage in reflective evaluation (Combs et al., 2009). By combining these ideas, students can identify the most effective and appropriate course of action. Using appropriate oral questions such as analysis, synthesis, and evaluation can also help develop critical and creative thinking in mathematics and indirectly enable the reflective aspect of judgment to be strengthened among the students. This indirectly encourages the students to think in a manner that is more convergent to solve various mathematical problems (Mahmud \& Yunus, 2018).

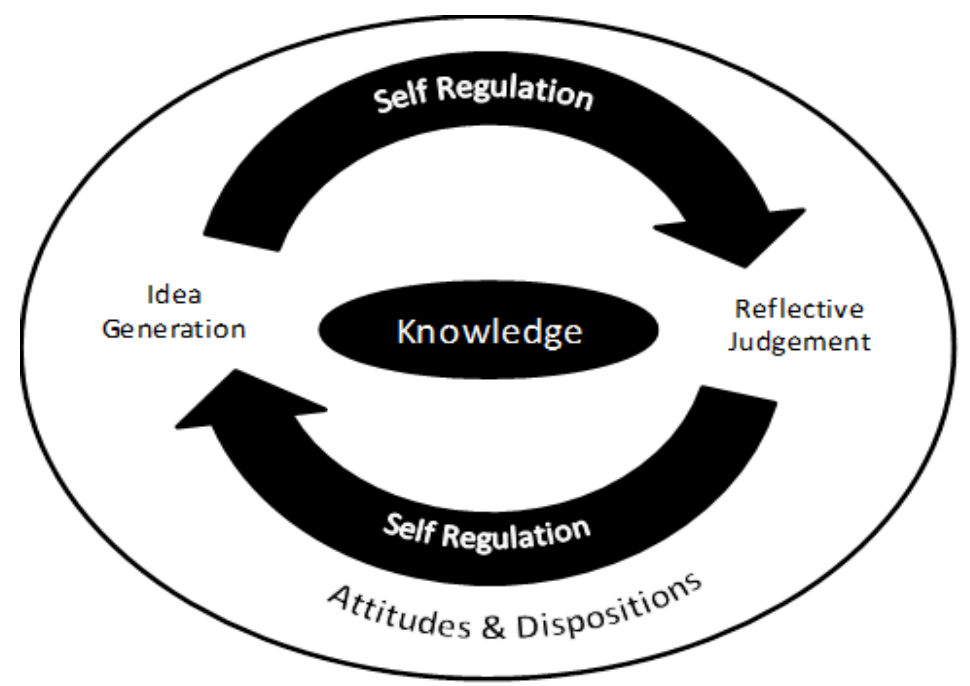

Figure 1: Conceptual model of critical and creative thinking processes (Combs et al., 2009)

Shahrill and Clarke (2014) stated that the reason for the decline in the students' performance in Malaysia in the global assessment of Trends in International Mathematics and Science Study (TIMSS) is the lack of oral questioning activities 
that can stimulate the students' thinking. The students found the questions used in the TIMSS test challenging, which focuses more on exploratory questions. This is where students need to remember and understand select mathematical facts. However, they need to connect their knowledge and make explicit judgments when solving these mathematical problems.

The use of oral questions by teachers may be less appropriate. Understanding mathematical concepts can be difficult to master, and teachers cannot improve their students' level mathematics learning in isolation (Kaya et al., 2014). Moreover, the types of questions posed by mathematics teachers also explore the students' existing knowledge in association with the topics discussed to a lesser extent, especially abstract concepts. Studies by Belcher (2016) and (Mahmud \& Yunus, 2018) showed that teachers prefer to ask convergent rather than divergent questions that can elicit the students' thinking in the teaching of mathematics. The use of convergent questions cause the students not to diverge and consequently not to develop (Shahrill, 2013).

In addition, mathematics teachers generally prefer to use low or medium cognitive level questions only and pay less attention to high cognitive level questions. This results in mathematics teaching activities that implement less stimulation of the students' thinking (Alhassora et al., 2017). Huang and Li (2009) stated that the lack of knowledge and skills in oral questioning among mathematics teachers make it difficult for them to construct high-level questions in mathematics teaching. Also, the poor pedagogical knowledge possessed by mathematics teachers also makes them unable to diversify the types of oral questioning to improve the students' mathematical thinking (Mahmud et al., $2020 \mathrm{~b}$ ). This causes mathematics teachers not to blend the content of mathematics lessons that are presented to the students into questions that encourage the students to think actively.

There is a need for an in-depth study to understand how appropriate mathematical questions can be used by mathematics teachers to stimulate and improve students' thinking skills (Mahmud et al., 2020c). The lack of in-depth studies toward understanding the types of oral questions hinder the encouragement of students' thinking in mathematics. This also explains the importance of the implementation of this study. Studies that seek to identify and explain the types of oral questions that can improve the students' thinking skills can help gain a deeper understanding of the phenomenon and close the research gap.

\section{Methodology}

This study used qualitative research that employed multiple case study techniques (Merriam \& Tisdell, 2016). The chosen approach satisfied the needs of the research topic because it enabled the building of a comprehensive image and a thorough understanding of the implementation of oral questioning among mathematics teachers in primary schools. A total of six primary schools in a district in the Malaysian state of Selangor were chosen as the study sites to examine and understand the practice of the teachers' oral questioning during 
mathematics lessons. The district was chosen as the study location based on Marshall and Rossman's (2014) criteria, which holds that the study location should be easy to access, have no barriers to conducting the study, provide a high probability of collecting in-depth data, provide the freedom to conduct the research, and be accessible to the study participants.

Purposive sampling was used in this study to determine and select the study participants by defining some of the criteria determined by the researcher (Marshall \& Rossman, 2014). The criteria used to select the participants were designed to ensure that those chosen had substantial information about the issues studied (Merriam \& Tisdell, 2016). The study participants were teachers who taught mathematics in primary schools and were willing to participate in the study. A total of six primary school mathematics teachers from six different schools were chosen.

The researcher divided the data collection process into two phases. The first phase concerned obtaining consent from the parties involved, planning the work, inventorying the equipment, refining the interview protocols, and conducting an observation (Merriam \& Tisdell, 2016). The second phase consisted of the data collection. The researchers made observations, conducted interviews, analyzed documents, and took field notes. The diverse data collection methods helped the researchers triangulate the data in the analysis stage, bolstering the conclusions reached (Miles et al., 2014).

The researchers used a constant comparative analysis method to deduce the patterns and themes from the data collected for this study, which served as the primary data (Kolb, 2012). The researcher inductively constructed a model through continuous comparison by categorizing, coding, refining, and connecting the data categories (Miles et al., 2014). Constant comparison is critical in qualitative research because it enables the researcher to examine the similarities and differences between the individual themes. In this method of data encoding, the data are broken down to be screened and then interpreted meaningfully to generate a theme. This method is critical for assisting the researchers in reorganizing the data into classifiable 'chunks', followed by grouping together the portions associated with specific research questions and themes.

The researcher used three types of coding to organize the qualitative data: open coding, axial coding, and selective coding. Similar themes were grouped into a single category, and the comparison process was repeated until the data reached saturation (Marshall \& Rossman, 2014). All the coding processes were carried out using Atlas Ti. 8 software to simplify the management and accelerate analysis. Numerous strategies were used to increase the study's validity and reliability, including triangulation, participant consent, peer review, an audit trail, researcher bias, and a prolonged stay in the field.

\section{Findings}

The study participants ranged between 27 and 50 years old (Table 1). To protect the participants' confidentiality, the researcher used a pseudonym to represent 
each participant in this study. Teacher Ana, Teacher Nadia, and Teacher Ada were all in their twenties and had a combined teaching experience of less than four years. Teacher Raha, Teacher Azah, and Teacher Roza were over 40 years old and had an average of over 20 years' teaching experience. Each participant had earned a bachelor's degree in mathematics education. As a result, the participants were deemed to possess the necessary credibility, knowledge, and abilities to teach mathematics.

Table 1. Educational Background and the Teaching Experience of the Research Participants

\begin{tabular}{|l|c|c|c|c|c|c|}
\hline & Ana & Nadia & Ada & Raha & Azah & Roza \\
\hline Age & 28 & 27 & 28 & 46 & 50 & 44 \\
\hline Mathematics Teaching Experience & 4 & 3 & 4 & 20 & 23 & 23 \\
\hline Academic Qualification & $\begin{array}{l}\text { Bachelor's Degree in Mathematics with } \\
\text { Education }\end{array}$ \\
\hline
\end{tabular}

The study found that the participants used oral questions to drive the students to think more critically and actively in each mathematics activity. These questions are used to help students understand the topic better and to reinforce the concepts being taught. This is important to encourage the students to generate new ideas based on their reasoning and existing knowledge. There are different categories of questions used to drive and stimulate the students to think, such as motivational questions, reflective questions, and questions asking for clarification.

\section{a) Prompting Questions}

Teachers generally use prompting questions as an alternative to encourage the students to provide more information on the topic being discussed. In this context, the teacher guides the students' thinking through questions that encourage the proliferation of thinking. This allows the student to provide a continuous response during the teaching process. Teachers often use questions like this to encourage communication between the teachers and students while also increasing the level of students' involvement.

The following are examples of how prompting questions are used in mathematics teaching:

Teacher Do we have another method? Other methods? Can anyone answer?

Student (All students silent without giving any answer)

Teacher Can we parse the numbers? Can it or not?

Student Yes we can.

Teacher Okay, but how?

[Roza, P1/8352-8875] 
Teacher Today we will learn about perimeter.

Student Measure the circumference.

Teacher How to measure the circumference?

Student The sum of all the sides.

Teacher Okay good. Which sides? Do we have to add all the sides?

Student Yes. All the sides.

[Ada, P1/5843-5877]

The passage is an example of how Teacher Roza and Teacher Ada use prompting questions to guide the students' thinking and to encourage the students to provide more information while interacting with their teachers. In addition, the questions also encourage the students to give more continuous responses to the matters discussed [Roza, NL/17082018].

Teacher Roza explained this in the following passage:

"Besides that, question after question should be given as an encouragement for students to increase communication with teachers on an ongoing basis. Students will provide more information on the topic being discussed." [Roza, SRI 3/594-905]

Moreover, Teacher Azah stated that prompting questions are important to maintain the momentum of the mathematics teaching process. This is because students are usually lazy or negligent in class due to the lack of interaction between teachers and students. The students will also always think to answer the questions asked by the teacher on an ongoing basis. This will indirectly create more active students.

The passage illustrates the description:

"These students, if we just teach without asking them questions, they will start to be lazy or careless. That is why they should always ask them so that the teaching momentum can be maintained. Apart from that, we want them to talk and have a two-way interaction with the teacher. We want the student to be active, to encourage him to speak and dare to give answers." [Azah, SRI3/367-740]

The question was also found to encourage the students' interest. It helped them to share their thoughts and to make the class activities more meaningful. 
The following are excerpts from Teacher Ada's teaching:

Teacher Okay, what kind of cube is this? (teacher draws a cube shape on the whiteboard). Well, the cube shape has the same side size of length. What is the shape of the cube that you can find in this class?

Student (A students point his finger at something)

Teacher That is not a cube. What are the things that have cube shapes that you have ever seen in your daily life?

Student The shape of a cake?

Teacher Okay good... Other than that?

Student Box of cake?

Teacher Yes, a box of cakes. Some more?

Student Milk carton.

Teacher Okay. What object has a dot on it? One dot, two dots, three dots

Student It is a dice.

b) Reflective Questions

[Ada, P3/1464-2221]

Teachers also ask reflective questions in mathematics teaching. Reflective questions are questions given by the teachers in response to the answers given by the students. This type of question requires the students to rethink the response they gave. The following are examples of how reflective questions are used:

Teacher Okay, who remembers the formula of the area?

Student Length times width times height.

Teacher Haaa! Length times width times height? Is it true?

Student Length times width times base times height.

Teacher Haha, how much do you multiply?

Student Length times width.

Teacher Yes, length times width. Very good, Isya.

[Ada, P2/2055-2192]

Teacher Ada uses reflective questions to help the students clarify their thinking and to explore the origins of their thoughts in turn. Teacher Ada asked a question about the general rectangular formula in which the students gave incorrect answers to the questions posed. Teacher Ada asked reflective questions as a way for the students to think about and correct the mistakes they had made. This indirectly encourages the students to reflect on their answers if the answers given are incorrect. In this context, reflective questions are used to stimulate the students' thinking rather than providing direct corrective feedback. Reflective questions were also used by other teachers, including Teacher Ana [Ana, P3/16167-16246], Teacher Roza [Roza, P3/9313-9467], and Teacher Azah [Azah, P3/1173-1189].

Reflective questions were also found to increase the students' confidence in the answers given and to help them rethink the answers given to the questions posed. This was explained by Teacher Azah "... so that they are confident with their answers and so that they rethink and calculate correctly..." [Azah, SRI1/4740- 
4970]. Teacher Ada noted that it was "For him to rethink whether it is correct or not that answer..." [Ada, SRI1/8558-8625].

Teacher Raha thought that the practice of asking reflective questions of the students can indirectly train them to always be careful when answering the questions asked. Indirectly, the probability of the teachers receiving the correct answer from the students will be increased: "We ask students again so that they are not in a hurry to answer the question, think correctly and carefully so that the answer given will be more accurate and less wrong" [Raha, SRI2/]. Usually, the students' answers will be repeated by the teacher in the form of a question.

The following is an example of how the question is applied in the teaching of mathematics:

Teacher What is the name of this shape?

Student Cuboid.

Teacher Cuboid? is it right?

Student Yes. It is a cuboid

Teacher Yes, right, it is a cuboid. This cuboid is made from a combination of rectangles.

[Raha, P1/3368-3384]

The passage shows that the teacher uses the student's answers to re-question the answers given. The question is given as a form of feedback to confirm the answers given by the students and to cultivate confidence in them when answering a question, as stated by Teacher Azah in the interview excerpt:

"We want to test them. For example, if they answer four and we ask them back, "is the answer four correct?", We want to see whether they are confident or not with their decision. If they are convinced, they will answer "Yes four". They will not change the answer to another."

[Azah, SRI 1/4085-4367]

The teachers also directed reflective questions to other students to encourage them to think about and confirm the answers given by their peers. This indirectly encourages more student involvement in the mathematics teaching process that is implemented.

Teacher All right, student, is that correct the way your friend wrote it?

Student Wrong.

Teacher Wrong? Right or wrong? Why is it wrong?

Student Right.

Teacher Just now, you said wrong? Well, I want to ask you, why is it wrong?

Student No meter units.

Teacher Yes... excellent, No meter units. There should be a unit here.

[Ana, P1/17180-17580]

Based on that example passage, Teacher Ana openly asked other students about their friends' answers. This was intended to help the other students reflect on the answers to the question. Reflective questions play an important role in guiding the students to reflect and think about the answers given to the teacher. Through this method, the students would be trained to be more careful and confident when 
answering the questions posed to them, and thus training them to evaluate the answers given.

\section{c) Clarification Questions}

The results also indicated that the study participants used questions to ask for explanations to clarify the students' thinking and to explore the origin of their thought on the content of the lessons.

The following is an example of how the teachers use questions to ask for explanations in mathematics teaching:

Teacher 15 meters (student answer question from teachers).

Student How do you get 15 meters?

Teacher 1.5 meters times 10, then I get 15 meters.

Student Okay, so the answer is 15 meters.

Teacher How to find the length of $M R, R S, S N$ ?

[Roza, P2/3049-3422]

Student We have to divide the total length by 3.

Teacher How do you know it has to be divided by 3?

Student Because it has three equal parts.

[Nadia, P1/9672-9831]

The researchers found that the teachers used explanatory questions to ask the students to explain how they obtained their answers. In turn, they helped the students strengthen their understanding and thinking on the topic that was being discussed. Teacher Roza stated that by asking the students to explain their answers, the students could better understand the content of the discussion, thereby also helping the teachers assess the level of learning that the students have achieved:

"When we ask students to explain their answers, they will remember and understand what they are students. In addition, it can provide an opportunity for teachers to assess students' levels of understanding."

[Roza, SRI3/1166-1400]

In addition, the questions asking for clarification also played a role in helping the teachers obtain information and to understand the extent of the development and level of understanding of the students of the content discussed [Azah, NL/18102018]. This information was used by the teachers as assessment-related information to help them to make decisions regarding the teaching process implemented. Teacher Azah explained that it was "... so we can assess students' knowledge, and from there we can decide to continue or want to repeat" [Azah, SRI 1/2570-2953].

Teacher Raha believed that asking for explanations allows other students to benefit from the explanations given by their peers. This indirectly helps the other students understand the content of the lesson. He explained: "Other students will also benefit and can help strengthen their understanding of the topic being studied" [Raha, SRI3/1438-1846]. Teacher Ada also expressed the same opinion as Teacher Raha. The questions asking for clarification would help improve the other 
students' understanding of the lesson content being discussed [Ada, SRI 2/1612916272]. That implies that mathematics teachers ask questions to help the students clarify their understanding and thinking on the content of the lesson discussed. The students are allowed to think more deeply and to clarify their understanding of the topic being discussed. The questions asking for clarification also help teachers assess the student's learning. This helps teachers make decisions on the teaching process implemented.

\section{Discussion}

This study's findings show that mathematics teachers ask guiding questions, prompting questions, reflective questions, and clarification questions. This form of questioning aims to ensure that the students' thinking is directed towards the topic being discussed. It encourages more information to be provided by the students themselves in the oral questioning activities carried out. Chin (2007) also used prompting questions to get more responses from the students. In this context, the prompting questions given by the teacher allow the students to provide more responses about the topic being discussed. This allows the teachers to build a more active communication environment while increasing the level of student engagement. Iksan and Daniel (2015) mentioned that getting a response during the teaching process can be overcome by always asking oral questions that encourage students to think together. This includes instructing students to provide more information on the topics discussed.

In addition, the use of prompting questions was also found to coincide with one of the basic standards of $21^{\text {st }}$ century education practices, which emphasizes that mathematics teaching should encourage students to jointly participate in the teaching process (Institut Aminuddin Baki, 2017). In this context, the teacher does not limit the views and ideas of the students but provides an open opportunity to voice their ideas. This is done in a structured manner since the teacher guides it. This is important to ensure that the discussion focuses on the actual scope of the content and allows more information to be provided by the students. In addition, prompting questions posed by the teachers can indirectly help maintain the momentum of the teaching process. This ensures that an active learning environment can be created that is more fun for everyone involved (Curriculum Development Division, 2014).

Furthermore, this study also found that teachers use reflective questions to help students rethink the answers given to the teacher. This is to make the answers given more accurate. In this context, reflective questions are used by teachers to help the students clarify their thinking and to explore the origin of their thoughts regarding the response given. Not only that, but this also plays a role in increasing the students' confidence when answering the questions posed by the teacher. This is because they are given ample opportunity to think though the problem and answer it better. Reflective questions are repeatedly given to indirectly train students to constantly question themselves as to whether the answers they gave are correct or not. In this way, the students' thinking can be guided towards a better understanding of concepts, while improving their metacognitive ability. 
From another aspect, the reflective questions used by teachers to guide the students' thinking serve to promote waiting time or 'wait time'. This is where the teachers give the students time to rethink the answers given to the teachers without the teacher stating whether the answer given is right or wrong. This can help improve the quality of the student's answers and to increase the number of students who are willing to answer the question if the question is spread throughout the class (Larson \& Lovelace, 2013).

This study also found that the participants asked questions for clarification. Teachers use clarification questions by asking them to explain more about the answers that students gave. In this context, the teacher asks the students to think again and to justify the answers given. This is to ensure that the students understand the responses that they give to the questions posed. It also prevents the students from answering the questions casually without thinking or just guessing. This means that asking questions to clarify the student's knowledge can encourage high-level thinking and communicative competence. This includes explaining argumentation and justification, which is a requirement for students to participate in meaningful and genuine conversational exchanges in the classroom (Gaspard, 2013).

By incorporating clarification questions into their lessons, teachers can assist their students in developing their reasoning and problem-solving abilities. This is as well as engaging them in meaningful conversations that stimulate and accelerate their learning acquisition (National Council of Teachers of Mathematics [NCTM], 2017). The NCTM (2014) proposed adding Fermi questions into mathematics instructions to encourage a range of approaches, to emphasize process over product, and to encourage non-traditional problem-solving strategies. Mathematics teachers must also provide opportunities for the students to demonstrate their mathematical knowledge and abilities through tasks with a high cognitive demand, requiring problem-solving and reasoning, as well as the exploration of alternative strategies and solution paths (NCTM 2017).

In addition, the study also shows that teachers use questions for clarification to help the teachers obtain information. This includes understanding the extent of development and the level of understanding of the students on the topics discussed. In this context, questions asking for explanation serve as formative assessments because the teachers can gather information about the students' learning and thus implement interventions and improvements in the future (Henning et al., 2012; Veon, 2016). This is something that is emphasized by the ministry where all aspects are considered when helping teachers decide on the results of the formative assessments implemented. This is so that the lessons provided improve the student's holistic learning (Malaysian Examinations Board, 2014)

\section{Conclusion}

The implementation of effective oral questioning is shown to play a significant role in ensuring that students' thinking skills can be developed during mathematics classes. Using the correct type of oral questions can help train 
students to diversify aspects of their thinking when it comes to understanding the content of the lessons presented (Mahmud et al., 2020c). Students can expand their abilities by engaging in dynamic reasoning and heuristics to solve various mathematical problems. This includes training them to look at various issues in their mathematics learning from various angles.

This study has significant implications, especially on teachers' teaching practice. It is argued that oral questioning in mathematics teaching should be expanded to improve the students' critical thinking skills rather than focusing on procedural questioning only. Although procedural questioning is a type of questioning that is commonly used in the teaching of mathematics, the questioning methodology should be optimized. It should also focus on questioning to train students to think in a more divergent manner (Kira et al., 2013). Moreover, this study also expands our understanding of how oral questioning helps encourage students to think in relation to improving the pedagogical practice in mathematics teaching. The results of this study also show a need for more studies on the construction of modules that emphasize the implementation of high-level oral questioning. The module can also be used by the students at the Institute of Teacher Education and by new teachers as a learning reference and practical guide. Finally, the outcomes of this study generated a large amount of data on the phenomena of oral questioning when teaching mathematics. This was used to develop the students' thinking skills. As a result, and since this is a qualitative study focused on a small number of cases, a quantitative follow-up study is recommended to see whether the findings can be generalized to other groups.

\section{References}

Alhassora, N. S. A., Abu, M. S., \& Abdullah, A. H. (2017). Inculcating higher-order thinking skills in mathematics: Why is it so hard? Man in India, 97(13).

Belcher, J. O. (2016). Effectiveness Of A Formative Assessment Initiative On Student Achievement In Eighth Grade Math (Issue January). Missisippi College.

Çelik, A. Ö., \& Güzel, E. B. (2016). A Mathematics Teacher's Questioning Approaches for Revealing Students' Thinking during Lesson Study. Turkish Journal of Computer and Mathematics Education, 7(2), 365-392.

Chin, C. (2007). Teacher questioning in science classrooms: Approaches that stimulate productive thinking. Journal of Research in Science Teaching, 44(6), 815-843.

Combs, L. B., Cennamo, K. S., \& Newbill, P. L. (2009). Toward A Conceptual Model Of Creative And Critical Thinking Processes. Developing Critical and Creative Thinkers, 49(5), 3-14.

Curriculum Development Division. (2013). Bahan Sumber Peningkatan Kemahiran Berfikir Aras Tinggi Matematik: Panduan Penggunaan Soalan Programme For International Student Assessment (PISA) [Mathematics High Thinking Skills Improvement Resource Materials: Guide to Using Program Questions For Inter. Ministry of Education Malaysia.

Curriculum Development Division. (2014). Elemen KBAT Dalam Pentaksiran [HOTS Element in Assessment]. Kementerian Pendidikan Malaysia.

Desli, D., \& Galanopoulou, E. (2017). Questioning in Primary School Mathematics: An Analysis of Questions Teachers Ask in Mathematics Lessons. 3rd International Symposium on New Issues on Teacher Education, 97.

Gaspard, C. (2013). Secondary Mathematics Student Teachers' Questions and Responses in 
Whole Class Discussion: Influences on Instructional Decisions. Tesis Doktor Falsafah yang tidak diterbitkan, University Of California.

Hassan, S. R., Rosli, R., \& Zakaria, E. (2016). The Use of i-Think Map and Questioning to Promote Higher-Order Thinking Skills in Mathematics. Creative Education, 07(07), 1069-1078.

Henning, J. E., McKeny, T., Foley, G. D., \& Balong, M. (2012). Mathematics discussions by design: Creating opportunities for purposeful participation. Journal of Mathematics Teacher Education, 15(6), 453-479.

Huang, R., \& Li, Y. (2009). What matters most: A comparison of expert and novice teachers' noticing of mathematics classroom events. School Science and Mathematics, 112(7), 420-432.

Iksan, Z., \& Daniel, E. (2015). Types of Wait Time during Verbal Questioning in the Science Classroom. International Research in Higher Education, 1(1), 72-80.

Institut Aminuddin Baki. (2017). Panduan Pelaksanaan Pendidikan Abad ke-21. Kementerian Pendidikan Malaysia.

Kassim, N., \& Zakaria, E. (2013). Integrasi Kemahiran Berfikir Aras Tinggi dalam Pengajaran dan Pembelajaran Matematik: Analisis Keperluan Guru [Integration of High-Level Thinking Skills in the Teaching and Learning of Mathematics: An Analysis of Teacher Needs]. Jurnal Pendidikan Matematik [Journal of Mathematics Education], 3(1), 1-12.

Kaya, S., Kablan, Z., \& Rice, D. (2014). Examining question type and the timing of IRE pattern in elementary science classrooms. International Journal of Human Sciences, 11(1), 621-640.

Kira, E. S., Komba, S., Morogoro, Eugenia Kafanabo, \& Tilya, F. (2013). Teachers' Questioning Techniques in Advanced Level Chemistry Lessons: A Tanzanian Perspective. Australian Journal of Teacher Education, 38(12), 66-79.

Kolb, S. M. (2012). Grounded Theory and the Constant Comparative Method: Valid Research Strategies for Educators. Journal of Emerging Trends in Educational Research and Policy Studies, 3(1), 83-86.

Larson, L. R., \& Lovelace, M. D. (2013). Evaluating the Efficacy of Questioning Strategies in Lecture-Based Classroom Environments: Are we asking the right questions? Journal on Excellence in College Teaching, 24(1), 105-122.

Mahmud, M. S. (2019). The Role of Wait Time in the Process of Oral Questioning in the Teaching and Learning Process of Mathematics. International Journal of Advanced Science and Technology Vol., 28(16), 691-697.

Mahmud, M. S., \& Yunus, A. S. M. (2018). The Practice Of Giving Feedback Of Primary School Mathematics Teachers In Oral Questioning Activities. Journal of Advanced Research in Dynamical and Control Systems, 10(12), 1336-1343.

Mahmud, M. S., Yunus, A. S. M., Ayub, A. F. M., \& Sulaiman, T. (2020a). Enhancing Mathematical Language Through Oral Questioning in Primary School. International Journal of Learning, Teaching and Educational Research, 19(5), 395-410.

Mahmud, M. S., Yunus, A. S. M., Ayub, A. F. M., \& Sulaiman, T. (2020b). The use of oral questioning in inculcating values in mathematics for primary school students. Universal Journal of Educational Research, 8(3), 1-8.

Mahmud, M. S., Yunus, A. S. M., Ayub, A. F. M., \& Sulaiman, T. (2020c). Types of Oral Questions Used by Teachers in Mathematical Problem Solving Teaching in Primary School Mathematics Teaching. International Journal of Psychosocial Rehabilitation, 24(06), 2278-2292.

Malaysian Examinations Board. (2014). Buku Panduan Pengurusan dan Pengendalian Pentaksiran Berasaskan Sekolah [School-Based Assessment Management and Handbook]. Ministry of Education Malaysia. 
Marshall, C., \& Rossman, G. B. (2014). Designing Qualitative Research. SAGE Publications, Incorporated.

Merriam, S. B., \& Tisdell, E. J. (2016). Qualitative Research A Guide to Design and Implementation. Jossey-Bass Inc Pub.

Miles, M. B., Huberman, A. M., \& Saldana, J. (2014). Qualitative data analysis: A methods sourcebook. SAGE Publications, Incorporated.

Shahrill, M. (2013). Review of Effective Teacher Questioning in Mathematics Classrooms. International Journal of Humanities and Social Science, 3(17), 224-231.

Shahrill, M., \& Clarke, D. J. (2014). Brunei Teachers' Perspectives on Questioning: Investigating the Opportunities to "Talk" in Mathematics Lessons. International Education Studies, 7(7).

Veon, K. E. (2016). A Case Study of Teachers' Practices using Formative Assessment for Fifth Grade Mathematics Students (Issue February). Unpublished doctoral dissertation, Northcentral University.

Wong, K. Y. (2015). Use of Student Mathematics Questioning to Promote Active Learning and Metacognition. In S. J. Cho (Ed.), Selected Regular Lectures from the 12th International Congress on Mathematical Education (pp. 877-895). Springer International Publishing. 